\title{
The thermal properties of Erythritol/Adipic acid composite phase change material
}

\author{
Shile Shen ${ }^{1}$, Shujuan $\operatorname{Tan}^{1, *}$, Guoyue $\mathrm{Xu}^{1}$, Tengchao Guo ${ }^{1}$ \\ ${ }^{1}$ College of Material Science and Technology, Nanjing University of Aeronautics and Astronautics, \\ 29 Jiangjun Road, Nanjing 211106, China \\ *Corresponding author, tanshujuan@nuaa.edu.cn
}

Keyword: Thermal storage performance; Erythritol; Adipic acid; Temperature-history

\section{Abstract}

A series of binary mixtures of adipic acid (AA) and erythritol (Ery) were prepared and the thermal properties were investigated in this study. The results showed that a eutectic mixture was formed when the mass ratio of adipic acid and erythritol reached 1:7. The eutectic mixture displayed a melting point of $110.64{ }^{\circ} \mathrm{C}$ while maintaining a high latent heat of fusion $\left(\Delta \mathrm{H}^{\mathrm{sl}}=270 \mathrm{~J} / \mathrm{g}\right)$. After 8 heating/cooling cycles, the mixture reacted to an ester according to a Fourier transform infrared (FT-IR) spectroscopic analysis. It confirmed the esterification reaction. The new material still has a high melting enthalpy ( $>240 \mathrm{~J} / \mathrm{g})$.

\section{Introduction}

The technology of thermal energy storage (TES) plays a crucial role in the rational use of energy because it can allow a decoupling of the manufacture and request for thermal energy [1]. The using of phase change materials (PCM) is one of the most rational methods to TES because of their stable phase transition temperature and high energy storage density [2-5]. The potential uses of different materials, eutectics of organic compounds have been recently reported as PCM.

Recently, lots of attention has been paid to the development of new PCMs for TES applications at intermediate temperature $\left(100-200^{\circ} \mathrm{C}\right)$. Hence, the use of sugar alcohols (SA) as a TES material has received a lot of consideration. Erythritol has gotten the most attention among all SA. It is characterized by relatively large melting enthalpy of $340 \mathrm{~J} / \mathrm{g}$ [6]. It has been used in many applications. For example, it has been used in waste-heat transportation [7], absorption refrigerating machine [8] and as an automotive cooling liquid waste heat storage system [9]. Erythritol may have serious undercooling as many other SA. However, Ona et al. [10] reported that ultrasound was an effective way to solve overcooling.

In general, the melting point of the PCM can be adjusted by adding impurities and disrupting the crystal arrangement. Another way of controlling the melting point is by single compounds mixing. It is well-known that a eutectic mixture has a lower melting point than either of its constituents while still melting congruently. The aim of this research was to obtain the PCM with high energy storage capacity and low melting point. In this study, a serious of binary mixtures of erythritol and adipic acid were prepared.

\section{Materials and methods}

Materials and binary systems employed. Adipic acid and meso-Erythritol were the compounds selected for the study. In order to promote the reproducibility of the results and to avoid uncertainties derived from impurities, analytical grade materials were employed. Adipic acid and meso-Erythritol were purchased from Aladdin Industrial Corporation. The main characteristics of 
the used materials can be found in Table 1.

Table 1 Properties of the pure materials employed in the study

\begin{tabular}{llllllll}
\hline & Acronym & $\begin{array}{l}\text { CAS } \\
\text { number }\end{array}$ & Formula & $\begin{array}{l}\text { Purity } \\
{[\%]}\end{array}$ & $\begin{array}{l}\Delta \mathrm{H}^{\text {sl }}[\mathrm{J} \\
/ \mathrm{g}]\end{array}$ & $\begin{array}{l}\text { Molecular } \\
\text { weight [g/mol] }]\end{array}$ & $\begin{array}{l}\text { Melting } \\
\text { point }\left[{ }^{\circ} \mathrm{C}\right]\end{array}$ \\
\hline Adipic acid & AA & $124-04-9$ & $\mathrm{C}_{6} \mathrm{H}_{10} \mathrm{O}$ & $\geq 99$ & 258.8 & 151.57 & 151.0 \\
meso-Erythritol & Ery & $149-32-6$ & $\begin{array}{l}4 \\
\mathrm{C}_{4} \mathrm{H}_{10} \mathrm{O}\end{array}$ & 99 & 346.4 & 122.12 & 118.6 \\
& & & & & & & \\
\end{tabular}

Preparation of the binary mixtures. Erythritol and adipic acid were weighed at a mass ratio of 5/1, 7/1, 9/1, 11/1, 13/1, 15/1. In a typical procedure, a beaker containing a mixture of adipic acid and erythritol was immersed in a pre-heated silicone oil bath maintained at $140{ }^{\circ} \mathrm{C}$. When the two materials melted completely, they were stirred in a magnetic stirrer at $300 \mathrm{r} / \mathrm{min}$ for $30 \mathrm{~min}$ to make sure a homogenous mixing and then cooled down to the room temperature.

Differential scanning calorimetry (DSC). A Techcomp DSC30 was employed to determine the melting point and the latent heat of these samples used in this study. The scanning rate was $5 \mathrm{~K} / \mathrm{min}$. All experiments were performed under nitrogen with a flow rate of $50 \mathrm{~mL} / \mathrm{min}$. The DSC was calibrated for heat flow and temperature using indium, tin and zinc standards. Samples of about 12 mg were weighed by a SHIMADZU AUY120 analytical balance and placed into $\mathrm{Al}_{2} \mathrm{O}_{3}$ open crucibles. Phase change enthalpies were determined by the integration of the phase transition peaks of the thermograms.

FT-IR spectroscopy. Fourier transformation infrared (FT-IR) spectra were collected on a Spectrum GX-III. A resolution of 4 and the average of 120 automated scans from 400 to $4000 \mathrm{~cm}^{-1}$ were used to obtain the IR spectra. Moreover, FT-IR is carried out also before and after the cycling test to study their chemical stability and changes in the molecular scale, bonds and functional groups.

Temperature-history method. The temperature-history(T-history) method used was based on Chiu and Martin [11] with some procedural modifications. The temperature histories of 99\% pure Ery and AA were obtained. The schematics of the T-history experimental setup are shown in Fig. 1.

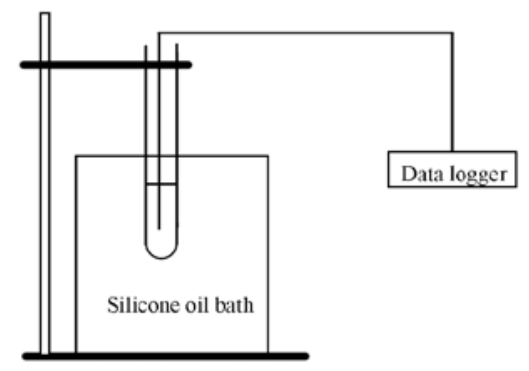

Fig.1. Schematics of the setup

\section{Results and discussion}

Thermophysical properties. The DSC thermograms of each sample is shown in Fig. 2(A). The amount of AA in the mixture decreases as the data are viewed from top to bottom in Fig. 2(A). Analysis of the data recorded for pure Ery and AA revealed endothermic signals that corresponded to the melting process of the respective samples. The heat of fusion and the melting point were determined from the melting curve data. For Ery and AA, the melting points were observed at $118.6^{\circ} \mathrm{C}$ and $151.6^{\circ} \mathrm{C}$, respectively. The area below the melting curve corresponded to the heat of fusion of that compound and was measured to be 346.4 and $258.8 \mathrm{~J} / \mathrm{g}$ for Ery and AA, respectively. The aforementioned melting points and heats of fusion for the pure Ery and AA were consistent with values reported in the literature [12, 13]. 
The thermograms shown in Fig. 2(A) revealed that physical mixtures of erythritol and adipic acid displayed one endothermic signals for all compositions explored.
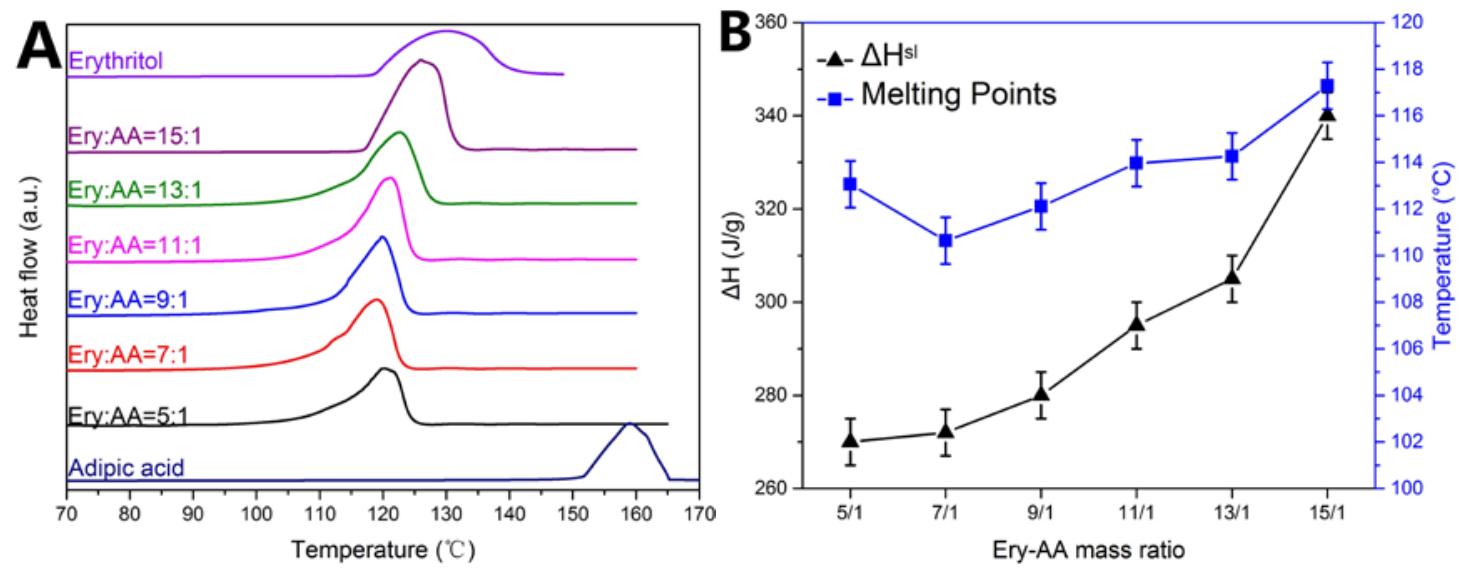

Fig.2. (A) DSC melting curves of the samples, (B) DSC Test Results of Ery-AA

The DSC test results of Ery-AA show in Fig. 2(B). When the mass ratio of Ery-AA is 7/1 the melting point is the lowest. With the mass ratio of adipic acid decreased, the latent heat of melting was increasing. The relationship between the mass ratio of AA and the melting point presents a ' $V$ ' type. From the curve, it can be seen that the melting point decrease when the mass ratio of Ery/AA is less than 7/1. However, the melting point rises up when the mass ratio of Ery/AA is more than $7 / 1$.

Thermal cycling tests. Fig. 3 showed the changes in latent heat of Ery/AA composites on repeated melting and freezing cycles. It could be seen that the latent heat of the binary mixtures decreased during thermal cycling. However, the latent heat values decreased up to the 5th cycle. In the subsequent cycles, the values remained almost constant.

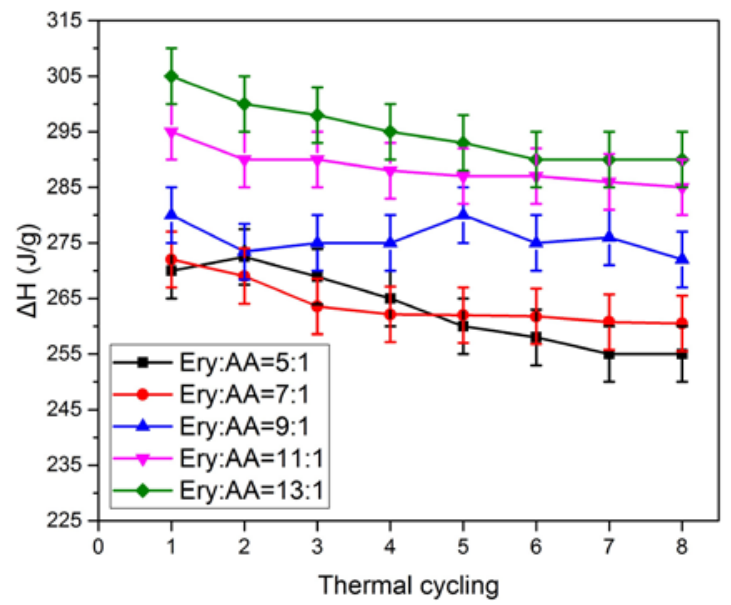

Fig. 3. Changes in latent heat of Ery-AA composites with thermal cycling

FT-IR spectroscopy. FT-IR analyses of erythritol, adipic acid, and Ery-AA are given in Fig. 4(A). As can be seen from Fig. 4(c), the stretching vibration peak in $1059.9 \mathrm{~cm}^{-1}$ is generated by $-\mathrm{OH}$ (Primary alcohol). The stretching vibration peak in $1081.9 \mathrm{~cm}^{-1}$ is generated by $-\mathrm{OH}$ (Secondary alcohol). The $-\mathrm{OH}$ vibration bands of erythritol were observed in the range of $3000-3350 \mathrm{~cm}^{-1}$. As it can be seen from the spectrum of adipic acid, the peak at $1697 \mathrm{~cm}^{-1}$ belongs to the $-\mathrm{C}=\mathrm{O}$ group. Compared with Fig. 4(a) and (c), there are no other different peaks in Fig. 4(b). It is indicated that there is not new functional group. 

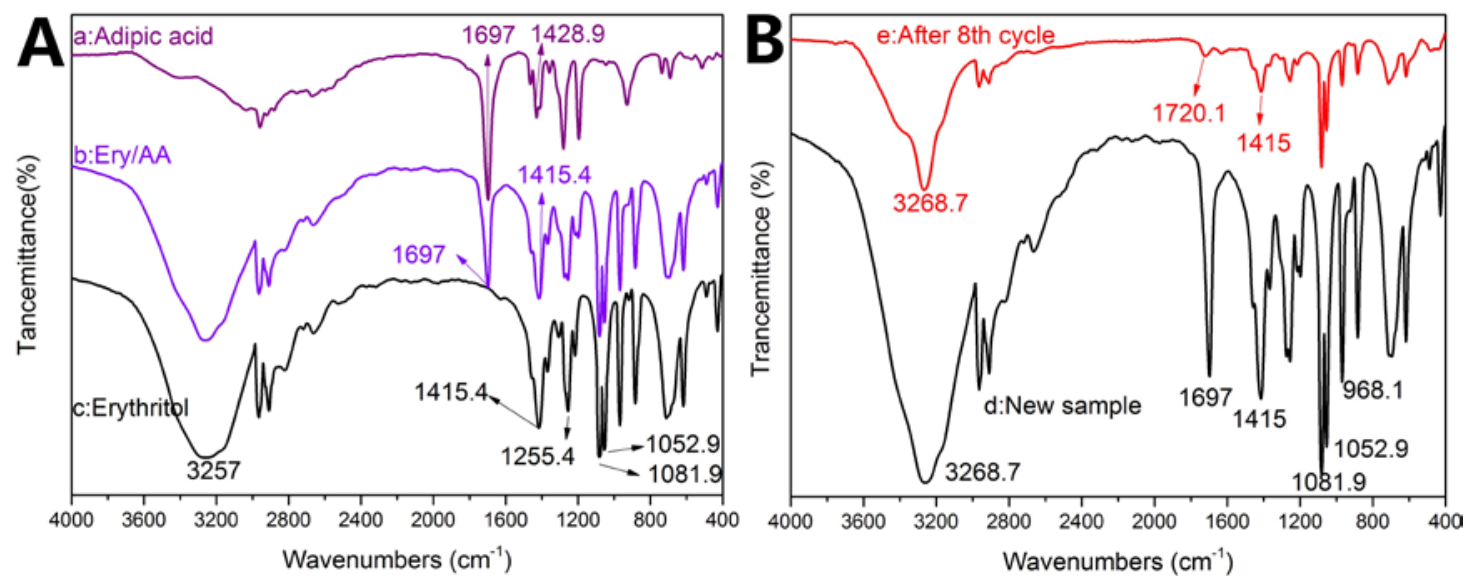

Fig. 4. (A) FT-IR spectra for erythritol, adipic acid, and Ery-AA, (B) FTIR spectra of the eutectic mixture(d) before being subjected to the DSC experiments described in the text (e) after being subjected to 8 DSC heating/cooling cycles.

FT-IR measurements were performed on the aforementioned mixtures that were tested for their cyclic stabilities, as shown in Fig. 4(B). The FT-IR spectra acquired for the mixture before and after 8 heating and cooling cycles, under an atmosphere of nitrogen. Compared with Fig. 4(d) and (e), the disappearance of the characteristic absorption peaks of $-\mathrm{C}=\mathrm{O}$ at $1697 \mathrm{~cm}^{-1}$ in Fig. 4(d) demonstrates that the carbonyl group in adipic acid had translated into ester bond. The carbonyl peaks of the Fig. 4(e) observed at $1720.1 \mathrm{~cm}^{-1}$ confirm the esterification reaction. Esters can also be used as a PCM to energy storage.

T-history characterization of selected materials. As can be seen from Fig. 5, the melting points of the mixture were found to be between around $100-120^{\circ} \mathrm{C}$. The melting point of erythritol was found to be $118{ }^{\circ} \mathrm{C}$. Adipic acid heating rate is the fastest because of the temperature of oil is lower than the melting point of adipic acid. With the mass ratio of erythritol increased, the thermal controlling performance of phase change material was becoming better.

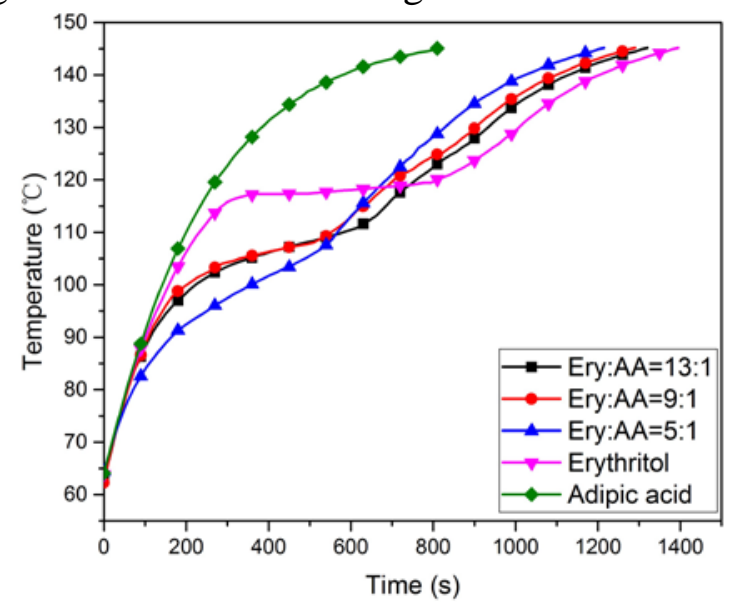

Fig. 5. The temperature-history of the PCMs.

\section{Concluding remarks}

The binary systems of Erythritol-Adipic acid with different mass ratio were prepared and characterized in this study.

Ery-AA mixture which was prepared by using Adipic acid of $12.5 \mathrm{wt} \%$ and Erythritol of $87.5 \mathrm{wt} \%$ has a melting temperature of $110.64{ }^{\circ} \mathrm{C}$. The latent heat of melting for Ery-AA mixture was obtained to be $270 \mathrm{~J} / \mathrm{g}$. We could control the melting points of the binary mixture by controlling the mass ratio of adipic acid. 
From FT-IR analysis, it was concluded that Ery-AA mixture would set off the esterification reaction. The new material still has a high energy density $\left(\Delta \mathrm{H}^{\mathrm{sl}}>240 \mathrm{~J} / \mathrm{g}\right)$.

With the mass ratio of erythritol increased, the thermal controlling performance of phase change material was becoming better.

\section{Acknowledgement}

The authors would like to acknowledge the support of the National Natural Science Foundation of China (Grant Nos: 51403102), the Natural Science Foundation of Jiangsu Province, China (Grant Nos: BK20140811), Fundamental Research Funds for the Center Universities (Grant Nos: NS2014058) and the Priority Academic Program Development of Jiangsu Higher Education Institutions (PAPD)

\section{References}

[1] Diarce G, Gandarias I, Á. Campos-Celador, et al. Eutectic mixtures of sugar alcohols for thermal energy storage in the $50-90{ }^{\circ} \mathrm{C}$ temperature range[J]. Solar Energy Materials \& Solar Cells, 2015, 134(3):215-226.

[2] Abhat A. Low temperature latent heat thermal energy storage: Heat storage materials[J]. Solar Energy, 1983, 30(4):313-332.

[3] Tyagi V V, Kaushik S C, Tyagi S K, et al. Development of phase change materials based microencapsulated technology for buildings: A review[J]. Renewable \& Sustainable Energy Reviews, 2011, 15(2):1373-1391.

[4] KamilKaygusuz. The Viability of Thermal Energy Storage[J]. Energy Sources, 1999, 21(8):745-755.

[5]Karaipekli A, Sarı A. Capric-myristic acid/vermiculite composite as form-stable phase change material for thermal energy storage[J]. Solar Energy, 2009, 83(3):323-332.

[6] Kakiuchi H, Yamazaki M, Yabe M, et al. A Study of Erythritol as Phase Change Material[J].

[7] Kaizawa A, Maruoka N, Kawai A, et al. Thermophysical and heat transfer properties of phase change material candidate for waste heat transportation system[J]. Heat and Mass Transfer, 2008, 44(7):763-769.

[8] Agyenim F, Eames P, Smyth M. Experimental study on the melting and solidification behaviour of a medium temperature phase change storage material (Erythritol) system augmented with fins to power a $\mathrm{LiBr} / \mathrm{H} 2 \mathrm{O}$ absorption cooling system[J]. Renewable Energy, 2011, 36(1):108-117.

[9] Shon J, Kim H, Lee K. Improved heat storage rate for an automobile coolant waste heat recovery system using phase-change material in a fin-tube heat exchanger[J]. Applied Energy, 2014, 113(6):680-689.

[10] Ona E P. Influence of Ultrasonic Irradiation on the Solidification Behavior of Erythritol as a PCM[J]. Journal of Chemical Engineering of Japan, 2002, 35(3):290-298.

[11] Chiu J N W, Martin V. Submerged finned heat exchanger latent heat storage design and its experimental verification[J]. Applied Energy, 2012, 93(5):507-516.

[12] Hormansdorfer G. Latent heat storage material and use thereof: US, US4795580[P]. 1989.

[13] Haillot D, Bauer T, Kröner U, et al. Thermal analysis of phase change materials in the temperature range $120-150^{\circ} \mathrm{C}[\mathrm{J}]$. ThermochimicaActa, 2011, 513(1-2):49-59. 